\title{
An evaluation of empirical regression models for predicting temporal variations in soil respiration in a cool-temperate deciduous broad-leaved forest
}

\author{
Na-Yeon Lee ${ }^{1, *}$ \\ Institute for Basin Ecosystem Studies, Gifu University, Gifu 501-1193, Japan \\ ${ }^{1}$ Present adress: National Park Research Institute, Korea National Park Service, Namwon 590-811, Korea
}

Soil respiration $\left(R_{\mathrm{S}}\right)$ is a critical component of the annual carbon balance of forests, but few studies thus far have attempted to evaluate empirical regression models in $R_{\mathrm{s}}$. The principal objectives of this study were to evaluate the relationship between $R_{\mathrm{S}}$ rates and soil temperature (ST) and soil water content (SWC) in soil from a cool-temperate deciduous broad-leaved forest, and to evaluate empirical regression models for the prediction of $R_{\mathrm{S}}$ using ST and SWC. We have been measuring $R_{\mathrm{s}}$, using an open-flow gas-exchange system with an infrared gas analyzer during the snowfree season from 1999 to 2001 at the Takayama Forest, Japan. To evaluate the empirical regression models used for the prediction of $R_{\mathrm{S}}$, we compared a simple exponential regression (flux $=\mathrm{a} e^{\mathrm{bt}}$ : Eq. [1]) and two polynomial multiple-regression models (flux $=\mathrm{a} e^{\mathrm{bt}} \times(\theta v-\mathrm{c}) \times(\mathrm{d}-\theta v)^{\mathrm{f}}$ : Eq. [2] and flux $=\mathrm{a} e^{\mathrm{b} t} \times\left(1-(1-(\theta v / \mathrm{c}))^{2}\right)$ : Eq. [3]) that included two variables (ST: $\mathrm{t}$ and SWC: $\theta v$ ) and that utilized hourly data for $R_{\mathrm{S}}$. In general, daily mean $R_{\mathrm{S}}$ rates were positively well-correlated with ST, but no significant correlations were observed with any significant frequency between the ST and $R_{\mathrm{S}}$ rates on periods of a day based on the hourly $R_{\mathrm{S}}$ data. Eq. (2) has many more site-specific parameters than Eq. (3) and resulted in some significant underestimation. The empirical regression, Eq. (3) was best explained by temporal variations, as it provided a more unbiased fit to the data compared to Eq. (2). The Eq. (3) (ST $\times$ SWC function) also increased the predictive ability as compared to Eq. (1) (only ST exponential function), increasing the $R^{2}$ from 0.71 to 0.78 .

Key words: empirical regression model, soil respiration, soil temperature, soil water content, temporal variation, validation

\section{INTRODUCTION}

Soil respiration $\left(R_{\mathrm{S}}\right)$ is an important component of the annual carbon (C) balance of forests, as $R_{\mathrm{S}}$ is the second most important $\mathrm{C}$ flux after gross primary production and is the largest respiratory $\mathrm{C}$ flux at the ecosystem scale. Interest in the rate-controlling factors of $R_{\mathrm{S}}$ is growing because of the potential for climate change to increase the flux of $\mathrm{CO}_{2}$ from ecosystems to the atmosphere (Raich and Potter 1995). Information regarding the relationship between the $R_{\mathrm{S}}$ rate and the variables that drive it is also necessary for the development of the models of value for the assessment of climate-change effects and for the interpretation of the processes involved.

The $R_{\mathrm{S}}$ rate is characterized by sizeable seasonal fluctuations owing to seasonal changes in root and microbial respiration. Although several biotic and abiotic factors influence root and microbial activity, the control exerted by soil temperature (ST), and in some cases soil water content (SWC), is generally dominant. In the absence of (c) This is an Open Access article distributed under the terms of the Creative Commons Attribution Non-Commercial License (http://creativecommons.org/licenses/by-nc/3.0/) which permits unrestricted non-commercial use, distribution, and reproduction in any medium, provided the original work is properly cited.
Received 17 February 2010, Accepted 18 March 2010

"Corresponding Author

E-mail: nayeon3@gmail.com

Tel: +82-63-630-7609 
water stress, variations in $R_{\mathrm{S}}$ account for the majority of the seasonal and diurnal variations in $R_{\mathrm{S}}$ rates. In areas in which water stress occurs frequently, $R_{\mathrm{S}}$ rates may not be correlated with ST, but rather with its SWC (Rout and Gupta 1989).

Microbial communities and plant root systems are particularly sensitive to changes in ST (Killham 1994). Both specific $R_{\mathrm{S}}$ rates and microbial and root biomass are affected positively by the evaluated ST, and in the majority of ecosystems a positive correlation between the $R_{\mathrm{S}}$ rate and ST is observed (Killham 1994), resulting in sizeable seasonal fluctuations in the flux rates. There is, however, currently no consensus regarding the exact form of the relationships (Lloyd and Taylor, 1994). The $R_{\mathrm{S}}$ rate has been modeled using linear (Witkamp 1966, Anderson 1973), power (Kucera and Kirkham 1971), and sigmoid (Schlentner and van Cleve 1985, Janssens et al. 1999, Matteucci et al. 2000) relationships with ST. Exponential relationships, most especially the $\mathrm{Q}_{10}$ relationship, are more frequently utilized to predict the $R_{\mathrm{S}}$ rates from ST (Raich and Potter 1995, Boone et al. 1998, Davidson et al. 1998).

However, ST is frequently correlated poorly with the $R_{\mathrm{S}}$ rate, and SWC may be the best predictor of $R_{\mathrm{S}}$ rates (Rout and Gupta 1989, Holt et al. 1990, Keith et al. 1997). SWC may negatively affect $R_{\mathrm{S}}$ rates when it becomes either very high (poor aeration and reduced $\mathrm{CO}_{2}$ diffusivity) or very low (desiccation stress) (Janssens et al. 2003). Even in ecosystems characterized by abundant rainfall, the $R_{\mathrm{S}}$ rate generally peaks in spring and after rainfall events (Matteucci et al. 2000, Lee et al. 2002). Field observations have shown a more variable relationship between the SWC and $R_{\mathrm{S}}$ rates. The response of the $R_{\mathrm{S}}$ rate to SWC has been successfully described using linear (Rout and Gupta 1989, Holt et al. 1990), exponential (Keith et al. 1997, Davidson et al. 1998), and polynomial functions (Bunnell et al. 1977, Schlentner and van Cleve 1985, Carlyle and Than 1988). However, Piñol et al. (1995) found SWC to be significant at one of their sites. Davidson et al. (1998) also suggested that SWC and ST controlled $R_{\mathrm{S}}$ as independent or confounded factors in a temperate mixed hardwood forest. Thus, these empirical models are site-specific, and only a few attempts have been made thus far to apply them to other locations.

Moreover, Hanson et al. (1993) and Janssens et al. (2003) determined, when including a moisture response function, that the empirical model fit the data better and more parsimoniously explained the temporal variability. However, only a relatively few studies have thus far evaluated empirical regression models, including SWC, in $R_{\mathrm{S}}$.
The principal objectives of this study were to evaluate the relationship between $R_{\mathrm{S}}$ rates versus ST and SWC using hourly and daily data collected for 1999 and 2001 in a cool-temperate deciduous broad-leaved forest, and to determine the empirical regression models for the prediction of $R_{\mathrm{s}}$.

\section{MATERIALS AND METHODS}

\section{Site description}

The study site is located on the northeast slope of Mt. Norikura, Gifu Prefecture, in central Japan $\left(36^{\circ} 08^{\prime}\right.$ $\mathrm{N}, 137^{\circ} 26^{\prime} \mathrm{E}, 1,430 \mathrm{~m}$ asl). The area is classified as cooltemperate and is located in a transitional zone between the Pacific side and the Japan Sea side of Japan. From 1980 to 2002, the annual mean air temperature was $6.1^{\circ} \mathrm{C}$ and the annual mean precipitation was $2,275 \mathrm{~mm}$ (Takayama Experimental Station, Gifu University; 1,342 $\mathrm{m}$ asl). The total rainfall varied from year to year, with a rainy season in June and a typhoon season in September. The site is covered with snow from December to April. The annual mean snowfall is approximately $600 \mathrm{~cm}$, and the maximum snow depth is 100 to $180 \mathrm{~cm}$ (data from Takayama Research Station).

Approximately 50-year-old secondary, deciduous broad-leaved forest composed mainly of Quercus crispula Blume and Betula ermanii Cham. grow at the site. In areas with brown forest soils (Dystric Cambisols) (Food and Agriculture Organization 1999), the forest floor vegetation consisted of Sasa senanensis Rehd., a bamboo. The trees produce leaf buds at the beginning of June, and the leaves begin to senesce in early October. The leaf area index of the forest is approximately 3.5 between the end of June and the end of September (Yamamoto et al. 1999).

The study site has also been one of the long-term flux monitoring sites in the AsiaFlux network established in 1993, with the cooperation of the National Institute of Advanced Industrial Science and Technology and Gifu University. The site description in this study has been previously detailed by Lee et al. (2006).

\section{Methodology}

The soil $\mathrm{CO}_{2}$ flux was measured at four points in the study site from September 1999 to September 2001. The soil respiration rate was determined via an open dynamic chamber technique similar to that described by Lee et al. (2002). During the spring growing season and the summer, measurements were taken every 2 weeks. During 
the autumn, measurements were made once per month, with just a few accidental interruptions (e.g. the electricity failed during a rainstorm). The open-flow IRGA method was utilized for the flux measurements. Ambient air $(50 \mathrm{~cm}$ from the soil surface) was passed through the chambers at a rate of $0.5 \mathrm{~L} / \mathrm{min}$. The carbon dioxide concentrations of the air being pumped into and withdrawn from each chamber in turn $(N=4)$ were measured via IRGA. One measurement cycle of 25 minutes was repeated for 24-48 hours. Methods for the soil respiration measurements have been detailed by Lee et al. (2002). The measuring system setup was comprised of one reference line and four identical sample lines, an IRGA in absolute mode (Li-6252; Li-Cor Biosciences, Inc., Lincoln, NE, USA) and a data logger (Model NR250; Keyence, Tokyo, Japan). The reference and sample lines were pneumatically independent of one another. In this system, the ambient air entered the chambers at a flow rate of 1.2-1.6 L/ min during the summer, and $0.8 \mathrm{~L} / \mathrm{min}$ during the winter. One measurement cycle of 25 minutes was repeated for 24-48 hours. During the $\mathrm{CO}_{2}$ analysis, air flow to the IRGA was maintained at a rate $0.5 \mathrm{~L} / \mathrm{min}$ lower than the chamber flow-through rate, and water vapor was removed prior to analysis with a perma-pure drier (MP-110-72P, ZBJ02502-72P; Fuji Electric Co, Ltd., Tokyo, Japan). The data logger recorded the electric output from the IRGA. Four chambers were placed 4-5 m apart. Each chamber consisted of two parts. The lower body, which featured two ports for the inlet and outlet of air, was a 15-cm-high PVC cylinder with an internal diameter of $21 \mathrm{~cm}$. When the bottom edge of the cylinder was pushed $4 \mathrm{~cm}$ into the soil, the bottom circumscribed an area of $346 \mathrm{~cm}^{2}$. The upper part, a $2.5-\mathrm{cm}$-high PVC lid, was placed on the top of the body immediately prior to the commencement of the measurements. Surface litter was contained within the chambers. However, great care was taken to avoid live or standing dead vegetation.

ST was measured in each chamber during the flux measurement at $5-10 \mathrm{~cm}$ below the top of the forest litter layer, which was approximately 4-8 $\mathrm{cm}$ below the surface of the mineral soil, depending on local variations in the thickness of the litter layer. Continuous ST measurements were conducted at two points near the flux measuring points at 30 minutes intervals $(1,10,20$, and $50 \mathrm{~cm}$ below the top of the litter layer) using copper-constantan thermocouples over the entirety of the study period. SWC was measured every 30 minutes by time-domain reflectometry (Model CS612; Campbell Scientific Inc., Logan, UT, USA). Two $15-\mathrm{cm}$ long rod-balanced probes were placed horizontally at soil depths of 15 and $40 \mathrm{~cm}$ below the top of the litter layer, as described by Davidson et al. (1998).

It is likely that ST and/or SWC in the surface soil layers fluctuates more widely than in deeper soil layers. In a previous study conducted at in our site, Mo et al. (2005) reported that the temperature of the upper soil may better predict daily soil carbon efflux than the temperature of the deeper soil, as the upper $20 \mathrm{~cm}$ of the soil could contribute greatly to the $R_{\mathrm{S}}$ rate, owing to the fact that it contained more than $90 \%$ of the roots (Lee et al. 2003) and a greater proportion of the microbial biomass (Mishima 2002). In the present study, therefore, $S T$ at $10 \mathrm{~cm}$ depth and SWC at $15 \mathrm{~cm}$ depth were used to derive the empirical regression models of the $R_{\mathrm{S}}$ rates.

Table 1 shows the list of ST and SWC response functions of the $R_{\mathrm{S}}$ rate that have been applied in the empirical models. In order to evaluate the ST response function, we fitted an exponential relationship (Eq. [1]) using the data of hourly and daily mean $R_{\mathrm{S}}$ rates. To evaluate the SWC dependence, we selected the two SWC response functions, linear (Eq. [4]) and convex-shape relationships (Eq. [5]). To evaluate the empirical regression models used to predict RS, we conducted comparisons with a simple exponential regression (Eq. [1]) and two polynomial multiple-regression models (Eq. [2] and [3]) that included two variables (ST and SWC) that utilized hourly

Table 1. List of temperature and moisture response functions of soil respiration rate that have been applied in empirical models

\begin{tabular}{llll}
\hline Response & \multicolumn{1}{c}{ Relationship } & \multicolumn{1}{c}{ Equation } & No. \\
\hline ST & Exponential & Flux $(\mathrm{ST})=\mathrm{a} e^{\mathrm{bt}}$ & $(1)$ \\
\hline \multirow{2}{*}{ ST, SWC } & Polynomial & Flux $(\mathrm{ST}, \mathrm{SWC})=\mathrm{a} e^{\mathrm{b} t} \times(\theta v-\mathrm{c}) \times(\mathrm{d}-\theta v)^{\mathrm{f}}$ & $(2)$ \\
& Multiple-regression model & Flux $(\mathrm{ST}, \mathrm{SWC})=\mathrm{a} e^{\mathrm{b} t} \times\left(1-(1-(\theta v / \mathrm{c}))^{2}\right)$ & $(3)$ \\
\hline \multirow{2}{*}{ SWC } & Linear & Flux $(\mathrm{SWC})=\mathrm{a} \theta v+\mathrm{b}$ & $(4)$ \\
& Convex-shape function & Flux $(\mathrm{SWC})=\mathrm{a} \theta v^{2}+\mathrm{b} \theta v+\mathrm{c}$ & $(5)$ \\
\hline
\end{tabular}

Flux (ST) = soil temperature response function, Flux $(\mathrm{ST}, \mathrm{SWC})=$ soil temperature and moisture response function, Flux $(\mathrm{SWC})=$ soil moisture response function, $t=$ soil temperature, $\theta v=$ soil water content, and $a, b, c, d$, and $f$ are constants.

$\mathrm{ST}$, soil temperature; $S W C$, soil water content. 
data for $R_{\mathrm{S}}$. Regressions using ST are denoted by $t$, and SWC is denoted by $\theta v$.

The significance for all statistical analysis was accepted at $P=0.05$. All statistical analyses were conducted using StatView ver. 5.0 (SAS Institute Inc., Cary, NC, USA).

\section{RESULTS AND DISCUSSION}

\section{Observed $R_{s}$ rates during 1999-2001}

From September 1999 through September 2001, the $R_{\mathrm{s}}$ rates increased from May to August and then decreased during autumn (Fig. 1). In 1999, the $R_{\mathrm{S}}$ rate was $600-900$ $\mathrm{mg} \mathrm{CO} \mathrm{m}^{-2} \mathrm{~h}^{-1}$ in early September, peaked at 700-1,300 mg $\mathrm{CO}_{2} \mathrm{~m}^{-2} \mathrm{~h}^{-1}$ in late September, and decreased to 30$300 \mathrm{mg} \mathrm{CO}_{2} \mathrm{~m}^{-2} \mathrm{~h}^{-1}$ in November (Fig. 1a). In 2000, the $R_{\mathrm{S}}$ rate was $20-200 \mathrm{mg} \mathrm{CO}_{2} \mathrm{~m}^{-2} \mathrm{~h}^{-1}$ in late April, increased to $200-400 \mathrm{mg} \mathrm{CO}_{2} \mathrm{~m}^{-2} \mathrm{~h}^{-1}$ in May, peaked at $400-900 \mathrm{mg}$ $\mathrm{CO}_{2} \mathrm{~m}^{-2} \mathrm{~h}^{-1}$ in June and August, and decreased to $200 \mathrm{mg}$ $\mathrm{CO}_{2} \mathrm{~m}^{-2} \mathrm{~h}^{-1}$ in November (Fig. 1b). In 2001, the $R_{\mathrm{S}}$ rate was 180-230 mg $\mathrm{CO}_{2} \mathrm{~m}^{-2} \mathrm{~h}^{-1}$ in May, peaked at 700-1,300 mg $\mathrm{CO}_{2} \mathrm{~m}^{-2} \mathrm{~h}^{-1}$ in June, and decreased to 700-1,100 mg $\mathrm{CO}_{2}$ $\mathrm{m}^{-2} \mathrm{~h}^{-1}$ in September (Fig. 1c). The $R_{\mathrm{S}}$ rates tended to be lower in 2000 than other years, possibly because of the slightly lower soil temperatures in 2000 (Lee et al. 2003).

In the Japanese cedar (Cryptomeria japonica D. Don) forest in our study watershed, Lee et al. (2008) reported that the temporal variation in $R_{\mathrm{S}}$ from soil and snow surfaces was measured continuously with an open dynamic chamber system. They investigated that the mean values of $R_{\mathrm{S}}$ rate obtained by all six chambers ranged between 255 and 1,529 $\mathrm{mg} \mathrm{CO}_{2} \mathrm{~m}^{-2} \mathrm{~h}^{-1}$, with lower values in midMay and at the end of November and higher values between the beginning of July and the middle of October. In a previous study conducted at our site, Mo et al. (2005) also reported that the daily average $R_{\mathrm{S}}$ rate was $245 \mathrm{mg}$ $\mathrm{CO}_{2} \mathrm{~m}^{-2} \mathrm{~h}^{-1}$ in late April, increased to $455 \mathrm{mg} \mathrm{CO}_{2} \mathrm{~m}^{-2} \mathrm{~h}^{-1}$ in mid May, peaked at $642 \mathrm{mg} \mathrm{CO}_{2} \mathrm{~m}^{-2} \mathrm{~h}^{-1}$ in late August, and decreased to $232 \mathrm{mg} \mathrm{CO}_{2} \mathrm{~m}^{-2} \mathrm{~h}^{-1}$ in November. Therefore, our values were comparable to the values reported by Mo et al. (2005) and Lee et al. (2008).

\section{ST versus $R_{S}$}

A temperature function used for the prediction of $R_{\mathrm{S}}$ was derived on the basis of 3 years of the Takayama Forest study. According to the daily mean data, Fig. 2a shows the relationship between the $R_{\mathrm{S}}$ rates $\left(\mathrm{g} \mathrm{C} \mathrm{m}^{-2}\right.$ day $\left.^{-1}\right)$ and ST was expressed as follows:

$$
\operatorname{Flux}_{\text {daily }}(\mathrm{ST})=0.406 e^{0.147 t}
$$

This regression accounted for $69 \%$ of the variation in the respiration measurements, primarily representing the seasonal changes in $R_{\mathrm{S}}$ at this site $(N=66)$. According to the hourly data, Fig. $2 \mathrm{~b}$ shows the relationship between

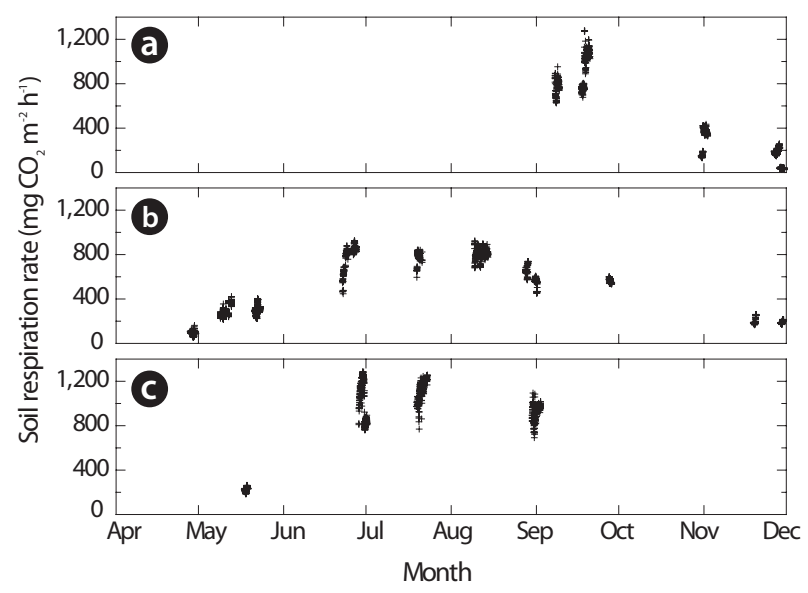

Fig. 1. Seasonal changes in hourly soil $\mathrm{CO}_{2}$ efflux $\left(R_{S^{\prime}} \mathrm{mg} \mathrm{CO}_{2} \mathrm{~m}^{-2} \mathrm{~h}^{-1}\right)$ in 1999 (a), in 2000 (b), and in 2001 (c).

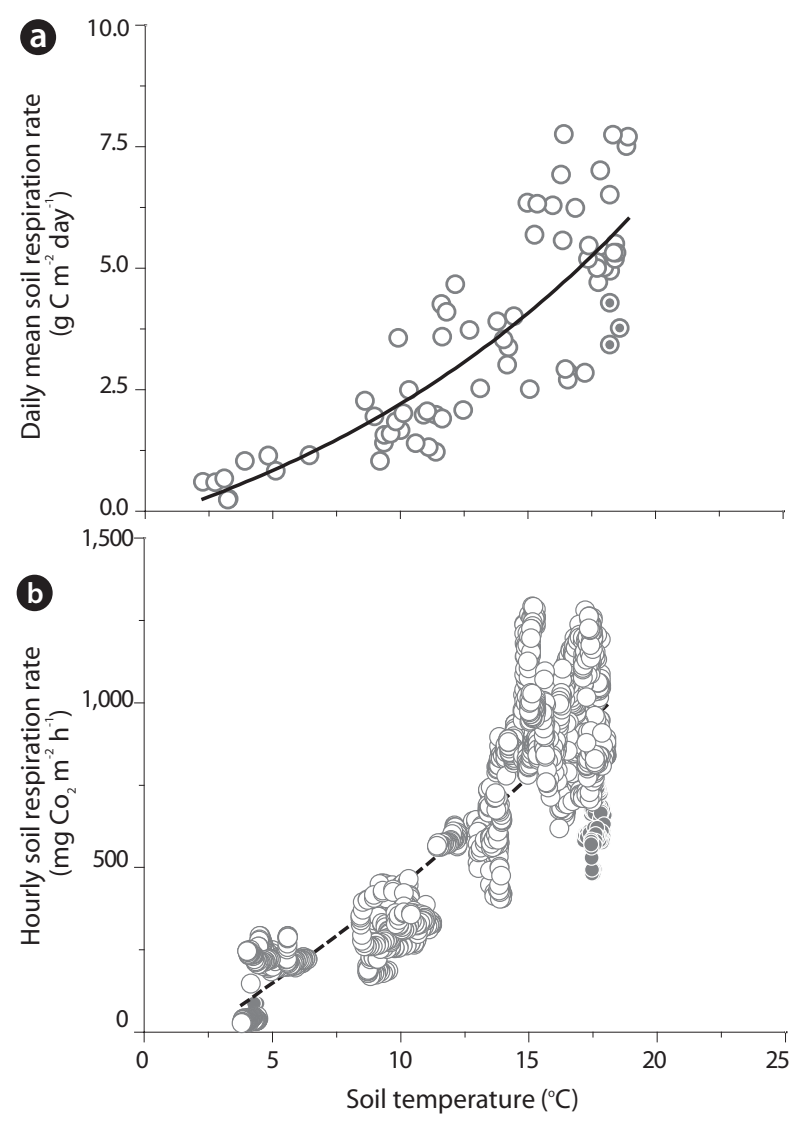

Fig. 2. Relationship between soil $\mathrm{CO}_{2}$ efflux $\left(R_{S}\right)$ and soil temperature daily-based data (a) and hourly-based data (b). The solid and dashed lines represent regression curves for daily and hourly data, respectively. 
the $R_{\mathrm{S}}$ rates $\left(\mathrm{mg} \mathrm{CO} \mathrm{m}^{-2} \mathrm{~h}^{-1}\right)$ and $\mathrm{ST}$ was expressed as follows:

$$
\text { Flux }_{\text {hourly }}(\mathrm{ST})=59.472 e^{0.163 t}
$$

Fig. $2 \mathrm{~b}$ shows that the relationship between $R_{\mathrm{s}}$ rates and ST on hourly data was also highly significant $\left(R^{2}=\right.$ $0.71, N=2,050$ ). These results demonstrated that ST was the primary factor driving temporal variations in $R_{\mathrm{S}}$.

In general, the daily mean $R_{\mathrm{S}}$ rates were positively well correlated with ST, but no significant correlations were noted to exist between the ST and $R_{\mathrm{S}}$ rates on the periods of a day based on the hourly $R_{\mathrm{S}}$ data. In our study site, no significant correlations were noted between the ST and hourly $R_{\mathrm{S}}$ rates recorded on a rainy day (Lee et al. 2002). They indicated that post-rainfall increases in the $R_{\mathrm{S}}$ rate represent approximately $16-21 \%$ of the annual soil carbon flux.

Fig. 3 shows that at $\mathrm{ST}>15^{\circ} \mathrm{C}$, there was considerable scatter in residuals both above and below the predicted $R_{\mathrm{S}}$ line for the function of ST (using the Flux ${ }_{\text {hourly }}$ (ST) equation). It appears likely that values above and below the predicted $R_{\mathrm{S}}$ line affected the SWC and/or rainfall conditions. Generally, it is fairly clear that ST was the main factor when $\mathrm{ST}<15^{\circ} \mathrm{C}$ (Figs. 1 and 3). It has been reported that when the ST was not limited, the SWC affects $R_{\mathrm{s}}$. Murayama et al. (2003) also reported that the variation in ecosystem respiration was relatively great when $\mathrm{ST}>15^{\circ} \mathrm{C}$; this was attributed to SWC and rainfall events occurring at our study site. They suggested that a single exponential or $\mathrm{Q}_{10}$ functional relationship of biological respiration to ST does not appear to be an adequate representation of biological respiration processes over the entire growing season, at least those occurring at this study site. Lloyd and Taylor (1994) also reported that the assumption of an exponential $\mathrm{Q}_{10}$ relation between $R_{\mathrm{S}}$ and ST is invalid and systematically results in underestimated fluxes at low temperatures, and overestimated fluxes at high temperatures.

Long-term continuous monitoring of $R_{\mathrm{s}}$ rates in situ is also urgently necessary to clarify the major sources of uncertainty in our ecosystem carbon balance. Opens and closes were automatic, and the measurements are based on an open-flow dynamic method (AOCC), providing continuous and semicontinuous measurements for investigating the temporal variations in $R_{\mathrm{S}}$ (e.g., Suh et al. 2006, Lee et al. 2008). The major advantages of continuous chamber systems are the availability of a series of data gathered over a long period of time, and measurements conducted under relatively undisturbed condi-

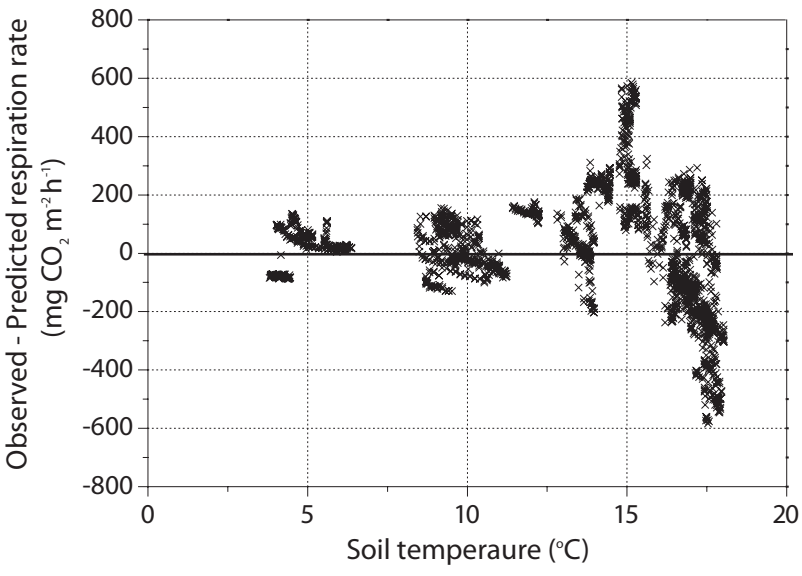

Fig. 3. Differences (observed - predicted $R_{5}$ ) in hourly soil $\mathrm{CO}_{2}$ efflux $\left(R_{S}\right)$. At soil temperature $(\mathrm{ST})>15^{\circ} \mathrm{C}$, considerable scatter in residuals both above and below the predicted $R_{S}$ line for the function of ST (using the Flux $_{\text {hourly }}(\mathrm{ST}$ ) equation).
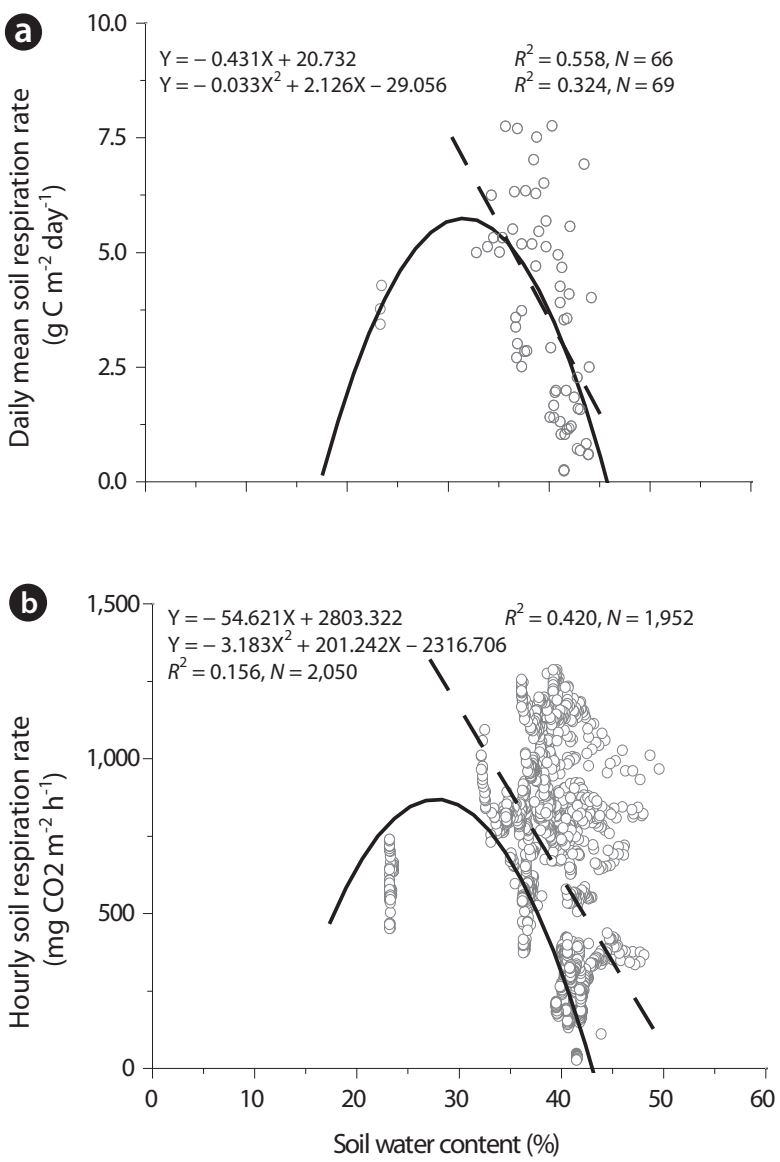

Fig. 4. Relationships between soil $\mathrm{CO}_{2}$ efflux $\left(R_{5}\right)$ and soil water content in daily-based data (a) and hourly-based data (b). The solid line represents the regression curve constructed from the whole dataset (with drought stress). The dashed line represents the linear function (without drought stress). The list of regressions (Eq. [4] and [5]) that were fitted to the data from daily means and hourly soil respiration rates and the obtained parameter values. Regressions are listed in Table 1. 
tions.

\section{SWC versus $R_{S}$}

We evaluated the relationships between soil respiration and SWC. In this investigation, when SWC ranged between 30 and 50\% (without drought stress), we applied a linear function (Eq. [4]). When SWC ranged between 20 and $50 \%$ (with drought stress), we applied a convex-shape function (Eq. [5]).

SWC evidenced significantly negative correlations to the daily mean and hourly $R_{\mathrm{S}}$ without drought stress. A SWC linear function accounted for approximately $56 \%$ of the $R_{\mathrm{S}}$ rate on the daily mean data $(P<0.001, N=66)$. With regard to the hourly data, we noted a significant linear relationship $\left(R^{2}=0.42, P<0.0001, N=1,952\right)$ with SWC. A convex-shaped function with optimal SWC on all data (with drought stress) explained approximately $32 \%$ of the daily mean data $(P<0.001, N=69)$ and $16 \%$ of the hourly data $(P<0.001, N=2,050)$. The relationship between SWC and $R_{\mathrm{S}}$ was described using a linear function, rather than a second-order polynomial function for water stress conditions (Fig. 4).

$R_{\mathrm{S}}$ rates achieved maximum values at SWC levels of approximately positive or convex-type relationships between SWC and $R_{\mathrm{S}}$ rates are rarely observed in actual field conditions, except during short-term drought or saturation conditions(Davidson et al. 1998, 2000) or hot-dry summer climate conditions (Xu and Qi 2001). A second-order polynomial function with optimal SWC explained an additional 16 to $32 \%$ of the temporal variability in $R_{\mathrm{S}}$ that could not be accounted for by ST alone. Our results indicated that SWC generates considerable scatter in residuals both above and below the predicted RS line for the function of ST. Kang et al. (2003) indicated that spatial variability in $R_{\mathrm{S}}$ is better explained with SWC than ST. Moderate drought may also partially explain the inter-annual variability in the $R_{\mathrm{S}}$ rate (Epron et al. 1999). Even in forests with less pronounced drought stress, in which drought occurs either infrequently or moderately, the inclusion of moisture regressions in empirical models will increase the degree to which the models fit the data.

\section{$\mathrm{ST} \times \mathrm{SWC}$ versus $R_{S}$}

To estimate ST $\times$ SWC versus the $R_{\mathrm{S}}$ model, we used the functions of Eq. (2) and (3) (Table 1). This model showed that the $R_{\mathrm{S}}$ rates increased with ST and were suppressed under dry or wet conditions.

Firstly, we utilized a multiple polynomial regression
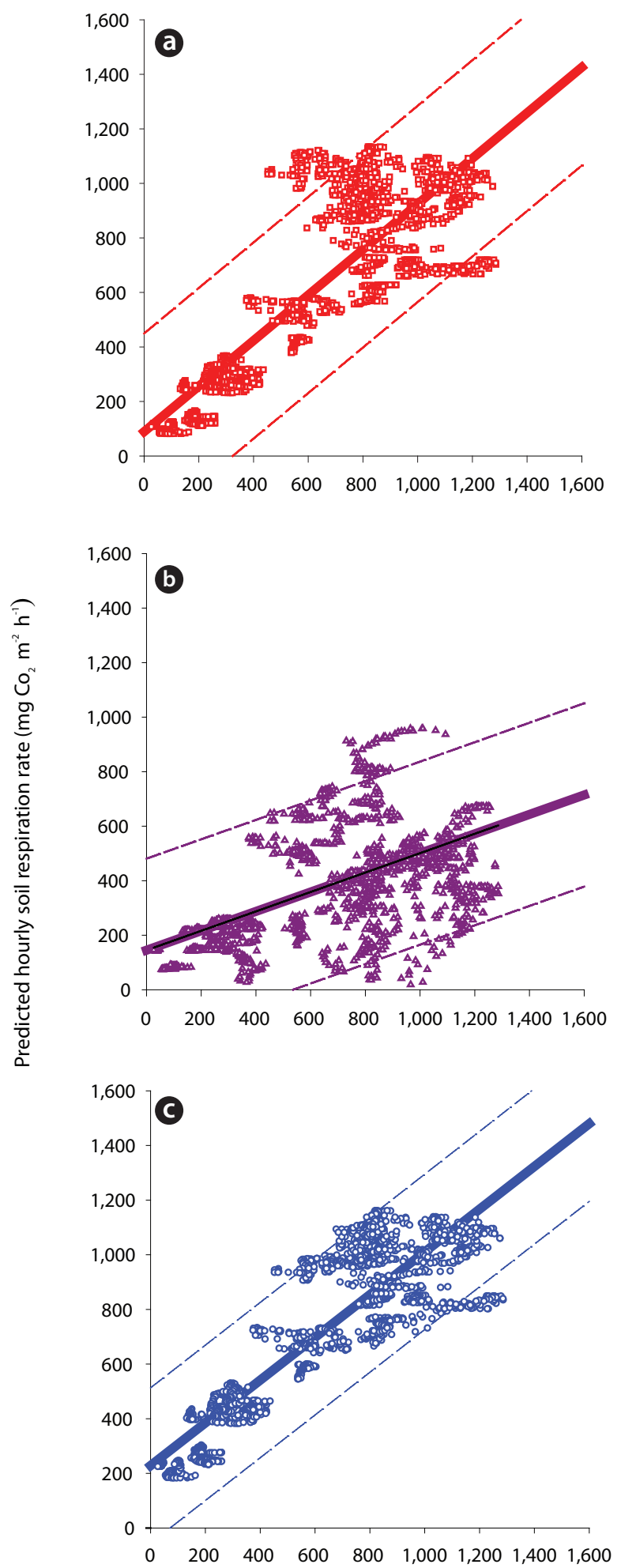

Observed hourly soil respiration rate ( $\mathrm{mg} \mathrm{Co} \mathrm{m}^{-2} \mathrm{~h}^{-1}$ )

Fig. 5. Relationship between the observed soil $\mathrm{CO}_{2}$ efflux $\left(R_{\mathrm{S}}\right)$ and predicted soil $\mathrm{CO}_{2}$ efflux $\left(R_{\mathrm{s}}\right)$ hourly data in temperature dependent on the exponential function (Eq. [1], a) and two polynomial multiple-regression models (Eq. [2], b and Eq. [3], c). The solid and dash lines represent the linear function and confidence limit (95\%). 
(Eq. [2]) of our previous study (Lee et al. 2002) using the hourly data recorded on sunny days (without rainfall effect) (Table 1). The data on rainy days and those obtained within 24 hours after the last rainfall were excluded from this calculation, thus eliminating the effects of rainfall on the $R_{\mathrm{S}}$.

$$
\operatorname{Flux}(\mathrm{ST}, \mathrm{SWC})=0.0000197 e^{0.45 t} \times(\theta v-21.42) \times(58.54-\theta v)^{4.46}
$$

The model explained approximately $96 \%$ of the variance in the daily soil carbon fluxes calculated from ST and SWC on sunny days during August 1999 to November 2000 (Lee et al. 2002). However, no significant relationship was detected between the observed and predicted $R_{\mathrm{S}}$ rates using all datasets. In order to validate the regression model, we used all of the data collected between September 1999 and September 2001. There was considerable scatter in residuals both above and below the predicted $R_{\mathrm{S}}$ line of the $\mathrm{ST} \times \mathrm{SWC}$ model $(\mathrm{Y}=0.35 \mathrm{X}+$ $145, R^{2}=0.34$ ) (Fig. 5b).

Second, we applied the other multiple polynomial function (with rainfall effect, period April-November 2000 and May-November 2001) (Lee et al. 2005) using the hourly all-dataset according to equation (3) (Table 1).

$$
\operatorname{Flux}(\mathrm{ST}, \mathrm{SWC})=146.8 e^{0.115 t} \times\left(1-(1-(\theta v / 37.5))^{2}\right)
$$

The ST $\times$ SWC model derived for the Eq. (3) function was also a good predictor $\left(\mathrm{Y}=0.78 \mathrm{X}+228, R^{2}=0.78\right)$, although not as good as a model derived specifically for the function Eq. (2) (Fig. 5c). The addition of a SWC function to the temperature-only model significantly increased the predictive power $\left(\mathrm{Y}=0.83 \mathrm{X}+89, R^{2}=0.71\right.$ for Eq. (1), Fig. 5a) $\left(R^{2}=0.78\right.$ for Eq. (3), Fig. $\left.5 \mathrm{c}\right)$.

Similarly, Savage and Davidson (2001) demonstrated that an empirical model utilizing both ST and SWC had good explanatory power in the Harvard forest $\left(R^{2}=0.64\right.$ for temperature-only model and $R^{2}=0.70$ for ST $\times$ SWC). Hanson et al. (1993) also demonstrated that the inclusion of SWC increased the predictive power of their model at four of their five sampling sites $\left(R^{2}\right.$ from $0.49-0.60$ increased to 0.67-0.73).

In the current study, Eq. (3) was best explained by temporal variations, as it provided a more unbiased fit to the data as compared to Eq. (2). The relatively modest increases in $R^{2}$ values when the SWC functions are added to the temperature-only regression models. The Eq. (2) has many more site-specific parameters than Eq. (3) and was significantly underestimated. The shape of the moisture response curve and the moisture content at which maximum respiration occurs depends on an array of site-specific factors such as soil texture and structure, amount and type of organic matter, and ST (Howard and Howard 1993).

Our values of the coefficients of $a$ and $b$ in Eq. (1) were $59.472\left(\mathrm{mg} \mathrm{CO}_{2} \mathrm{~m}^{-2} \mathrm{~h}^{-1}\right)$ and 0.163. In the Japanese cedar forest, however, the values were $360\left(\mathrm{mg} \mathrm{CO}_{2} \mathrm{~m}^{-2} \mathrm{~h}^{-1}\right)$ and 0.058 (Lee et al. 2008). Similarly, the parametrization of temperature functions is likely to be site-specific and to be confounded by other effects, such as interactions with water content. Temperature functions predicted seasonal variation in $R_{\mathrm{S}}$ fairly well, but variations in precipitation and SWC were identified as the key to understanding inter-annual variations. We will need to analyze the data of two consecutive wet years to determine whether or not high respiration rates persist during both years or if the high respiration rates only occur during the first wet year after a dry year. Our on-going measurements may also afford us other opportunities to investigate a broad range of interannual variability.

\section{ACKNOWLEDGMENTS}

The author would like to thank Prof. H. Koizumi of Waseda University for his encouragement and Dr. N. Saigusa of the National Institute of Environmental Studies for providing the long-term micrometeorological measurement data. The author also wishes to thank Prof. K. Nakane and Prof. T. Nakatsubo of Hiroshima University for their advice and assistance.

\section{LITERATURE CITED}

Anderson JM. 1973. Carbon dioxide evolution from two temperate deciduous woodland soils. J Appl Ecol 10: 361378.

Boone RD, Nadelhoffer KJ, Canary JD, Kaye JP. 1998. Roots exert a strong influence on the temperature sensitivity of soil respiration. Nature 396: 570-572.

Bunnell FL, Tait DEN, Flanagan PW, Van Cleve K. 1977. Microbial respiration and substrate weight loss: I. A general model of the influences of abiotic variables. Soil Biol Biochem 9: 33-40.

Carlyle JC, Than UB. 1988. Abiotic controls of soil respiration beneath an eighteen-year-old Pinus radiata stand in south-eastern Australia. J Ecol 76: 654-662.

Davidson EA, Belk E, Boone RD. 1998. Soil water content and temperature as independent or confounded factors 
controlling soil respiration in a temperate mixed hardwood forest. Global Change Biol 4: 217-227.

Davidson EA, Verchot LV, Cattânio JH, Ackerman IL, Carvalho JEM. 2000. Effects of soil water content on soil respiration in forests and cattle pastures of eastern Amazonia. Biogeochemistry 48: 53-69.

Epron D, Farque L, Lucot E, Badot PM. 1999. Soil $\mathrm{CO}_{2}$ efflux in a beech forest: dependence on soil temperature and soil water content. Ann For Sci 56: 221-226.

Food and Agriculture Organization. 1999. FAO STAT Statistical Database 1997. Food and Agriculture Organization, Rome.

Hanson PJ, Wullschleger SD, Bohlman SA, Todd DE. 1993. Seasonal and topographic patterns of forest floor $\mathrm{CO}_{2}$ efflux from an upland oak forest. Tree Physiol 13: 1-15.

Holt JA, Hodgen MJ, Lamb D. 1990. Soil respiration in the seasonally dry tropics near Townsville, North Queensland. Aust J Soil Res 28: 737-745.

Howard DM, Howard PJA. 1993. Relationships between $\mathrm{CO}_{2}$ evolution, moisture content and temperature for a range of soil types. Soil Biol Biochem 25: 1537-1546.

Janssens IA, Sampson DA, Cermák J, Meiresonne L, Riguzzi F, Overloop S, Ceulemans R. 1999. Above- and belowground phytomass and carbon storage in a Belgian Scots pine stand. Ann For Sci 56: 81-90.

Janssens IA, Dore S, Epron D, Lankreijer H, Buchmann N, Longdoz B, Brossaud J, Montagnani L. 2003. Climatic influences on seasonal and spatial differences in soil $\mathrm{CO}_{2}$ efflux. In: Fluxes of Carbon, Water and Energy of European Forests (Valentini R, ed). Springer-Verlag, New York, pp 235-256.

Kang SY, Doh S, Lee D, Lee D, Jin VL, Kimball JS. 2003. Topographic and climatic controls on soil respiration in six temperate mixed-hardwood forest slopes, Korea. Global Change Biol 9: 1427-1437.

Keith H, Jacobsen KL, Raison RJ. 1997. Effects of soil phosphorus availability, temperature and moisture on soil respiration in Eucalyptus pauciflora forest. Plant Soil 190: 127-141.

Killham K. 1994. Soil Ecology. Cambridge University Press, Cambridge.

Kucera CL, Kirkham DR. 1971. Soil respiration studies in tallgrass prairie in Missouri. Ecology 52: 912-915.

Lee MS, Lee JS, Koizumi H. 2008. Temporal variation in $\mathrm{CO}_{2}$ efflux from soil and snow surfaces in a Japanese cedar (Cryptomeria japonica) plantation, central Japan. Ecol Res 23: 777-785.

Lee MS, Mo WH, Koizumi H. 2006. Soil respiration of forest ecosystems in Japan and global implications. Ecol Res 21: 828-839.
Lee MS, Nakane K, Nakatsubo T, Koizumi H. 2003. Seasonal changes in the contribution of root respiration to total soil respiration in a cool-temperate deciduous forest. Plant Soil 255: 311-318.

Lee MS, Nakane K, Nakatsubo T, Koizumi H. 2005. The importance of root respiration in annual soil carbon fluxes in a cool-temperate deciduous forest. Agric For Meteorol 134: 95-101.

Lee MS, Nakane K, Nakatsubo T, Mo WH, Koizumi H. 2002. Effects of rainfall events on soil $\mathrm{CO}_{2}$ flux in a cool temperate deciduous broad-leaved forest. Ecol Res 17: 401409.

Lloyd J, Taylor JA. 1994. On the temperature dependence of soil respiration. Funct Ecol 8: 315-323.

Matteucci G, Dore S, Stivanello S, Rebmann C, Buchmann N. 2000. Soil respiration in beech and spruce forests in Europe: trends, controlling factors, annual budgets and implications for the ecosystem carbon balance. In: Carbon and Nitrogen Cycling in European Forest Ecosystems: Ecological Studies, Vol. 142. (Schulze ED, ed). Springer-Verlag, Berlin, pp 217-236.

Mishima SI. 2002. Microbial biomass, microbial respiration activity and $\mathrm{CO}_{2}$ flux derived by microorganisms in cool temperate secondary forest floor in Japan. In: Proceedings of the VIII INTECOL International Congress of Ecology, Seoul, pp 183-184.

Mo W, Lee MS, Uchida M, Inatomi M, Saigusa N, Mariko S, Koizumi H. 2005. Seasonal and annual variations in soil respiration in a cool-temperate deciduous broad-leaved forest in Japan. Agric For Meteorol 134:81-94.

Murayama S, Saigusa N, Chan D, Yamamoto S, Kondo H, Eguchi Y. 2003. Temporal variations of atmospheric $\mathrm{CO}_{2}$ concentration in a temperate deciduous forest in central Japan. Tellus B 55: 232-243.

Piñol J, Alcañiz JM, Rodà F. 1995. Carbon dioxide efflux and $\mathrm{pCO}_{2}$ in soils of three Quercus ilex montane forests. Biogeochemistry 30: 191-215.

Raich JW, Potter CS. 1995. Global patterns of carbon dioxide emissions from soils. Global Biogeochem Cycles 9: 2336.

Rout SK, Gupta SR. 1989. Soil respiration in relation to abiotic factors, forest floor litter, root biomass and litter quality in forest ecosystems of Siwaliks in northern India. Acta Oecol Oecol Plant 10: 229-244.

Savage KE, Davidson EA. 2001. Interannual variation of soil respiration in two New England forests. Global Biogeochem Cycles 15: 337-350.

Schlentner RE, van Cleve K. 1985. Relationship between $\mathrm{CO}_{2}$ evolution from soil, substrate temperature, and substrate moisture in four mature forest types in interior 
Alaska. Can J For Res 15: 97-106.

Suh SU, Chun YM, Chae NY, Kim J, Lim JH, Yokozawa M, Lee MS, Lee JS. 2006. A chamber system with automatic opening and closing for continuously measuring soil respiration based on an open-flow dynamic method. Ecol Res 21: 405-414.

Witkamp M. 1966. Decomposition of leaf litter in relation to environment, microflora and microbial respiration. Ecology 47: 194-201.
Xu M, Qi Y. 2001. Soil surface $\mathrm{CO}_{2}$ efflux and its spatial and temporal variations in a young ponderosa pine plantation in northern California. Global Change Biol 7: 667677.

Yamamoto S, Murayama S, Saigusa N, Kondo H. 1999. Seasonal and inter-annual variation of $\mathrm{CO}_{2}$ flux between a temperate forest and the atmosphere in Japan. Tellus B 51: 402-413. 